\title{
Hinweise und Zeichenerklärungen
}

\section{Zeichenerklärungen:}

-F/A: Hiermit werden hilfreiche Verweise auf andere Fragen und Antworten in diesem Buch markiert, die in einem thematischen oder terminologischen Kontext stehen, auch auf Links, die im Anhang aufgeführt sind.

Hinweise zu Literatur, Quellen, Abbildungen und Schreibweisen:

Alle Koranzitate in diesem Buch beziehen sich auf Übersetzungen von Rudi Paret, der als philologisch sehr guter Übersetzer gilt und deswegen von Muslimen wie Nichtmuslimen gleichermaßen geschätzt wird. Die in etlichen Suren in Klammern gesetzten Versteile sind Bestandteile seiner Übersetzungen.

Hadithe wurden der fünfbändigen Auswahl und Übersetzung von Adel Theodor Khoury entnommen.

Diese „heiligen Quellen“ sowie weitere Zitate und Namen von Autoren, auf die sich das Buch bezieht, sind mit näheren Angaben im Literaturverzeichnis hinterlegt.

Die Abbildungen und Tabellen sind - sofern keine Quelle genannt ist - eigene Darstellungen, bei Zitaten und Literaturverweisen sind die Verfasser samt Quellen angegeben.

In ihrer aus dem Arabischen eingedeutschten Form erscheinen häufig vorkommende Wörter wie ğihâd, halāl, hadîth, ramadān oder sunna in der wissenschaftlich üblichen Transkription, kursiv und durchweg mit kleinem Anfangsbuchstaben.

Das generische Maskulinum wurde oftmals durch das ästhetisch kritisierbare, aber Männer und Frauen einschließende *-Ungetüm ersetzt, so z.B. in „Schüler^innen“. 
